\title{
Spinal analgesia: where is the evidence?
}

\author{
Eduardo Bruera • David Hui
}

Received: 17 February 2010 / Accepted: 8 April 2010 /Published online: 12 June 2010

(C) Springer-Verlag 2010

\section{Dear Editor,}

We read with interest the systematic review by Myers and colleagues [1]. The authors conducted a thorough review of the literature on intraspinal techniques for pain management in cancer patients. They did a good job summarizing the existing studies and consensus. However, we would like to express our concerns regarding the authors' conclusions. Specifically, they stated in the abstract that "the evidence supported the use of intraspinal techniques for cancer pain management... Intraspinal techniques monitored by an interprofessional health care team should be included as part of a comprehensive cancer pain management program".

It is unclear how the authors arrived at these conclusions. The authors identified three randomized controlled trials comparing intraspinal with systemic analgesia [2-4]. The first study by Vanino et al. found no statistically significant difference in pain [2]; the second study by Smith et al. revealed a borderline statistical significance of questionable clinical value [3], while the third council study revealed no difference in pain control between epidural and subcutaneous administration of morphine [4]. The methodologic quality of the three included studies needs to be highlighted. Two studies reported no sample size calculations, and both appeared to be under-powered $[2,4]$. Two were open-label studies [2, 3] which could significantly affect how pain and side effects were assessed. Finally, all were supported by pharmaceutical companies. It is known that industry support is an important source of bias in clinical trials $[5,6]$.

The authors also wrote in their discussion that "the main advantages of intraspinal analgesia for cancer pain are the

\footnotetext{
E. Bruera $(\triangle) \cdot$ D. Hui

Department of Palliative Care and Rehabilitation Medicine-Unit

1414, University of Texas M.D. Anderson Cancer Center,

1515 Holcombe Blvd.,

Houston, TX 77030, USA

e-mail: ebruera@mdanderson.org
}

delivery of adequate pain control and fewer side effects than with the conventional analgesia routes. Disadvantages of intraspinal analgesia include the technically demanding insertion procedure and close patient follow-up required by skilled healthcare personnel". The authors may also want to emphasize the procedural risk and complications related the catheter and/or pump, such as infections, bleeding, and cerebrospinal fluid leak. The limited reporting of this important information could be potentially misleading.

Based on these findings, perhaps the most appropriate conclusion is that the role of intraspinal opioids for the management of cancer pain has not been established and that adequately powered, well-designed, independently funded clinical trials are required before this complex, risky, and expensive intervention becomes part of routine care.

\section{References}

1. Myers J, Chan V, Jarvis V, Walker-Dilks C (2010) Intraspinal techniques for pain management in cancer patients: a systematic review. Support Care Cancer 18(2):137-149

2. Vainio A, Tigerstedt I (1988) Opioid treatment for radiating cancer pain: oral administration vs. epidural techniques. Acta Anaesthesiol Scand 32(3):179-185

3. Smith TJ, Staats PS, Deer T, Stearns LJ, Rauck RL, Boortz-Marx RL, Buchser E, Català E, Bryce DA, Coyne PJ, Pool GE, Implantable Drug Delivery Systems Study Group (2002) Randomized clinical trial of an implantable drug delivery system compared with comprehensive medical management for refractory cancer pain: impact on pain, drug-related toxicity, and survival. J Clin Oncol 20(19):4040-4049

4. Kalso E, Heiskanen T, Rantio M, Rosenberg PH, Vainio A (1996) Epidural and subcutaneous morphine in the management of cancer pain: a double-blind cross-over study. Pain 67(2-3):443-449

5. Lexchin J, Bero LA, Djulbegovic B, Clark O (2003) Pharmaceutical industry sponsorship and research outcome and quality: systematic review. BMJ 326(7400):1167-1170

6. Bekelman JE, Li Y, Gross CP (2003) Scope and impact of financial conflicts of interest in biomedical research: a systematic review. JAMA 289(4):454-465 